\section{DIFFERENCE IN OUTCOME IN THE TRANSECTION OF THE PULMONARY ARTERY AND VEIN}

To the Editor:

We read with interest the article entitled, "Is Pneumonectomy Mandatory after Transection of the Left Main Pulmonary Artery?" by Dr Ihekweazu and colleagues ${ }^{1}$ in the July issue of Journal. We are interested in their experience, and we would like to make a few comments.

In fact, 2 articles have already been published on the transection of the main pulmonary artery. First, Dhaliwal and colleagues ${ }^{2}$ described 20 cases in which the main pulmonary artery and main bronchus were transected because of massive hemoptysis. They called the surgical procedure "physiological lung exclusion." In their series, the exclusion involved the entire left lung in 8 cases, the entire right lung in 6 cases, the right upper lobe in 3 cases, the left upper lobe in 2 cases, and the right lower lobe in 1 case. The pulmonary veins were left in all 20 patients to enable venous drainage. Dhaliwal and colleagues' method has been used in patients with life-threatening hemorrhage in the lung with failed medical management, in whom lung resection was found to be technically hazardous or even impossible. This article mentioned transection of not only the pulmonary artery but also the main bronchus. Second, Randolph ${ }^{3}$ described a similar case involving pulmonary hemorrhage in pulmonary tuberculosis, treated by main pulmonary artery ligation only. Randolph attempted a pneumonectomy, but could not complete it because of technical difficulties. However, he wrote that the patient had no recurrence of hemoptysis and no empyema.

In contrast, we have had the opposite experience, suggesting that the pulmonary vein cannot be transected like the pulmonary artery. When we ligated the pulmonary vein in a patient with primary lung cancer in the right upper lobe, we transected 2 of the 3 branches from the right upper lobe. On further inspection of the pulmonary artery and main bronchus, the tumor was deemed unresectable, so the thoracotomy was closed. Once the patient was extubated, hypoxemia developed and the chest $\mathrm{X}$-ray and computed tomography demonstrated pulmonary edema of the upper right lobe on postoperative day 3 . The respiratory failure worsened, and finally he died of pneumonia on postoperative day 11 . Thus, we can state that 1 of the 3 branches from the right upper lobe can be transected, but transection of 2 or more of the 3 branches should be avoided. Our experience tells us that 1 of the 3 pulmonary artery branches to the right upper lobe can be ligated.

\section{Mitsuhiro Kamiyoshihara, $M D, P h D$ Toshiteru Nagashima, MD Hitoshi Igai, MD, PhD Department of General Thoracic Surgery Maebashi Red Cross Hospital Maebashi, Japan}

\section{References}

1. Ihekweazu UN, Travis WD, Flores RM. Is pneumonectomy mandatory after transection of the left main pulmonary artery? $J$ Thorac Cardiovasc Surg. 2010;140:242-3.

2. Dhaliwal RS, Saxena P, Puri D, Sidhu KS. Role of physiological lung exclusion in difficult lung resections for massive hemoptysis and other problems. Eur J Cardiothorac Surg. 2001;20:25-9.

3. Randolph H. Haemorrhage in pulmonary tuberculosis as a surgical emergency. Chest. 1955;28:416-20.

doi:10.1016/j.jtcvs.2010.08.087

\footnotetext{
The Editor welcomes submissions for possible publication in the Letters to the Editor section that consist of commentary on an article published in the Journal or other relevant issues. Authors should: • Include no more than 500 words of text, three authors, and five references. - Type with double-spacing - See http://jtcs.ctsnetjournals.org/misc/ifora.shtml for detailed submission instructions. - Submit the letter electronically via jtcvs.editorialmanager.com. Letters commenting on an article published in the JTCVS will be considered if they are received within 6 weeks of the time the article was published. Authors of the article being commented on will be given an opportunity of offer a timely response ( 2 weeks) to the letter. Authors of letters will be notified that the letter has been received. Unpublished letters cannot be returned.
} 